\title{
Green Cover (Tree) Analysis of Chennai Metropolitan Area Using High Resolution Satellite Imagery
}

\author{
Venkatesan Chinnappa*, Murugasan Rajiah, Thirumalaivasan Devarajan \\ Institute of Remote Sensing, Anna University, Chennai, India
}

Received: 30 September 2020

Accepted: 25 January 2021

\begin{abstract}
Sustainable urban environment addresses the issues associated with the urban development due to the increase in land use/land cover (LU/LC) and decrease in forest and agricultural areas. As vegetation plays a major role in ecological, social, health, and economic benefits to the inhabitants of a city, urban greeneries should be monitored through the remotely sensed data with high resolution imagery for a sustainable urban development. The present study investigates the green cover (tree) change of Chennai Metropolitan Area (CMA) through the satellite data of Resourcesat-1 LISS IV and Resourcesat-2 LISS IV. CMA consists of approximately $426 \mathrm{~km}^{2}$ of urban area and $774 \mathrm{~km}^{2}$ of sub-urban area with many LU/LC categories like settlements, vegetation and open spaces. Green cover mapping with the accuracy assessment was carried out by using both digital image processing technique and on-screen visual interpretation (Google Earth imagery). Vegetation indices and texture analysis were employed to extract the green cover for 2005 and 2012, to which the change detection was applied. The results reveal that the green cover area of CMA administrative boundary decreased approximately by $1.18 \%$ for 2005-2012 and the actual green cover for 2012 reduced by $8.62 \%$. This analysis will be useful to the policy makers of urban development in planning infrastructure development projects and administrators of metropolitan cities, especially Chennai.
\end{abstract}

Keywords: green cover (tree), vegetation indices, texture analysis, change detection, urban environment

\section{Introduction}

In this fast-growing world, environmental degradation increases continuously and deliberately on the earth's surface due to the infrastructure developments in metropolitan cities, resulting in diminished urban green cover [1]. Intangible changes in the ecosystem

*e-mail: esan.cv@gmail.com influence the land cover in which urbanization is rapid due to the impervious surfaces like concrete and asphalt on vegetation cover. In addition, the land cover in the urban areas, which are warmer than their surroundings, affects the subsequent energy balance of the ecosystem and this phenomenon is known as urban heat island [2]. In fact, rapid urbanization due to increasing population and spatial extension transforms the natural cover into impervious islands [3]. Consequently, the forest land transforms into agricultural land, which in turn changes to industrial 
land and so on, setting in motion the degradation cycle of the environment and natural cover.

Land use planning of cities is an important policy issue and it relies on the ratio between urban land and green spaces, which influence public health as well. Unsound decisions of the land managers and policy makers using information about land cover for development can have a negative impact on the receiving environment [4]. Therefore, it is essential for urban planners to rely on detailed and updated knowledge of the vegetated areas for their balanced approach to development.

Green ways, parks, utilized fields, and residential landscaping may serve as urban green space. Green areas dependent on trees determine the quality of urban development with respect to pollution control, equilibration of water cycle and stability of the urban microclimate [5]. They provide the habitat for wildlife, lessen the urban heat island effects, pedestrian and bicycle transportation support, surface runoff and flood control, and erosion prevention and these are the positive key factors to assess the effect on green cover [6]. In contrast, decrease in green cover causes, among other things, high surface runoff and lowers infiltration, leading to floods associated with atmospheric changes [5].

Urban green space provides opportunities for outdoor recreation, enjoyment and simple pockets of vegetation in the city environment. Further, largescale industrial plantations could be outlined by visual delineation and updated annually [7]. Hence, mapping the urban green space gives necessary information for its effective management and protection. Urban studies, city forest inventories, ecology management and other urban planning applications are the primary components for the accurate assessment and classification of tree species [8-10].

Trees have a significant role in the urban green cover spaces with high impact on human habitation, as green cover (tree) is a critical component in the urban ecosystems. In addition, trees constitute the habitat for a variety of animals and insects, which may be a potential hazard for residents [11]. However, underground utility systems, surrounding power lines and serious allergies in local inhabitants affect roots, branches and flowering of certain species, respectively. Comprehensive high accuracy outputs obtained through ground survey mapping are not called for in all cases, as it is an enormously time-consuming activity [12]. In this context, remote sensing and GIS techniques have received increasing attention to study the mapping of land use/land cover (LU/LC) and change detection [13-16]. They can generate detailed, up-to-date, and accurate information about LU/LC for the planning and management of urban growth, addressing ecological issues associated with the settlements [1, 4]. Remote sensing data can provide information on vegetation structure, amount of biomass and leaf area as various indices are useful in estimating the vegetation cover
[17-18]. Recently, the application of remote sensing data on monitoring the changing pattern of vegetation has helped in assessing the vegetation condition from site-specific areas to regions or even larger areas, using image-processing techniques [19]. Photogrammetric assessment of aerial photography is useful to identify the tree species, though its accuracy is dependent on the interpretation based on the spatial discrimination criteria [20].

Classification uses the features (descriptors or criteria) of the objects. The highest ability to separate the targeted objects represents the ideal features, leading to highest within-class similarity and minimum overlap interclass. Spectral signatures, texture, Vegetation Indices (VI) and shape information, etc., are the common features, which fall into two approaches, namely pixel-based and object-based approaches [9, 21-22]. Remotely sensed data can capture foliageheight diversity and horizontal vegetation structure to calculate the sample-point pixel values and image texture measures [18, 23].

Spectral vegetation index is a simple and convenient approach to extract the information from the remotely sensed data, which are easy to analyze in large amount [24]. It is a combination of different spectral bands lying at the visible and near infrared (NIR) regions of the electromagnetic spectrum [19]. It provides significant results over other image classification methods [14, 25]. In fact, it enhances the information of spectral reflectance data by extracting the variability due to vegetation characteristics, such as vegetation canopy cover, Leaf Area Index (LAI), and the effects of soil, atmospheric condition and sur-target-sensor geometry $[24,26]$. The semi-analytical method of measuring the vegetation activity is suitable for detecting within-field spatial variability and useful in precision agriculture [19, 24, 27].

A statistical, geometrical, and model-based signal processing is useful for texture analysis [28]. This statistical approach considers local spatial or spectral variability and is one of the most popular texture approaches [9, 28-30]. Texture feature provides an improved classification by $5-15 \%$ compared to spectral cases [8, 31-33]. It is a key visual criterion for extracting information from the images of vegetation and forestry applications [34-35]. Researchers [36-37] have used Grey-Level Occurrence Matrix (GLOM) and GreyLevel Co-occurrence Matrix (GLCM) to recognize texture patterns. Further, an improved thematic map with better accuracy has been prepared for GLCM texture [38].

Vegetation structure is a major component of animal habitat that can be mapped using remotely sensed data [23]. Vegetation indices are both qualitative and quantitative measurements to identify the green cover, which is affected by atmosphere, sensor calibration, sensor viewing conditions, solar illumination geometry, soil moisture, color and brightness [19]. Normalized Difference Vegetation 
Index (NDVI) is one of the most widely used and reliable vegetation indices in monitoring vegetation change, emerging as a promising method to evaluate the green cover [39]. Google earth imagery is useful for the reliable validation of NDVI and semi-supervised image classification, which can save time and reduce cost [40]. Change detection in image processing indicates the difference of an object or phenomenon at different times and evaluates the change through variation in spectral response of vegetation or other cover type at a particular location [12-14]. Significant correlation of edaphic disturbances with the abundance of invasive alien species is derived using principal component analysis [41]. Principal components required to detail the sources of variance in the data can be assessed by taking Eigen values higher than one as a criterion [42].

Thus, this brief literature review reveals that there is a very limited research on the analysis of textural and biophysical features in terms of vegetation indices to classify and map the urban vegetation/ green cover. Further, texture feature classification has rarely been used in combination with spectral signature. Hence, this study addresses the assessment of the green cover mapping in the context of LU/LC for urban planning, development and management with reference to Chennai Metropolitan Area.

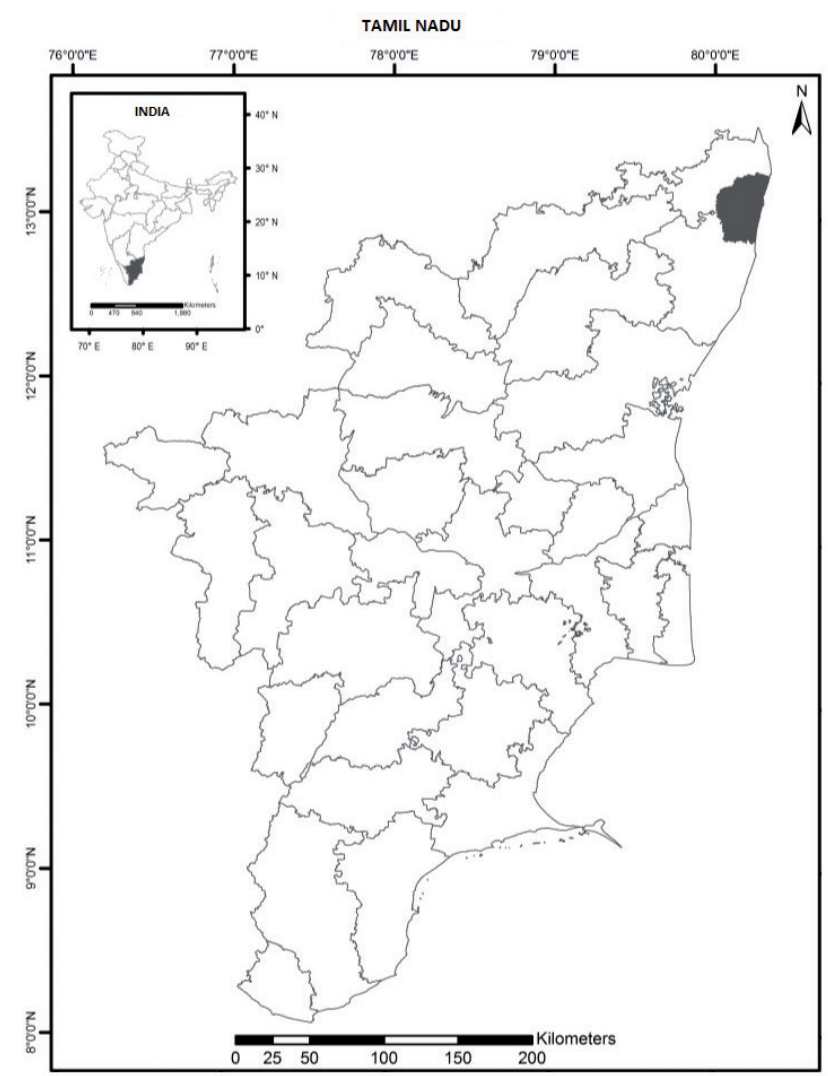

\section{Material and Methods}

Study Area

Fig. 1 depicts the study area of the fast growing metropolitan city Chennai, $\left(13^{\circ} 5^{\prime} 2^{\prime \prime} \mathrm{N}, 80^{\circ} 16^{\prime} 12^{\prime \prime} \mathrm{E}\right)$, the capital of Tamil Nadu state in India. This area expanded from $176 \mathrm{~km}^{2}$ to $426 \mathrm{~km}^{2}$ in 2011 with a variety of LU/LC categories, such as human settlements, vegetation and open spaces. Greater Chennai Corporation has incorporated the suburban areas into city limits for development purposes. As of 2020, the approximate total area, administrated by Chennai Metropolitan Development Authority (CMDA), is $1200 \mathrm{~km}^{2}$ [43]. According to 2011 census, 4.68 million residents live in the city making it the sixth populous city in India [44]. However, the green cover of Chennai city is $6.25 \%$, which includes $5 \mathrm{~km}^{2}$ of moderately dense forest and $4 \mathrm{~km}^{2}$ of open forest [45].

Chennai Metropolitan Area (CMA) comprises the Metropolis and sub-urban areas of Thiruvallur and Kanchipuram districts. However, this study considers St Thomas Mount, Kunrathur, Kattankolathur and Sriperumbudur blocks of Kanchipuram district, Thiruvallur, Villivakkam, Poonamallee, Puzhal, Sholavaram and Minjur blocks of Thiruvallur District and Chennai Corporation as individual zones in the CMA for the purpose of image analysis.

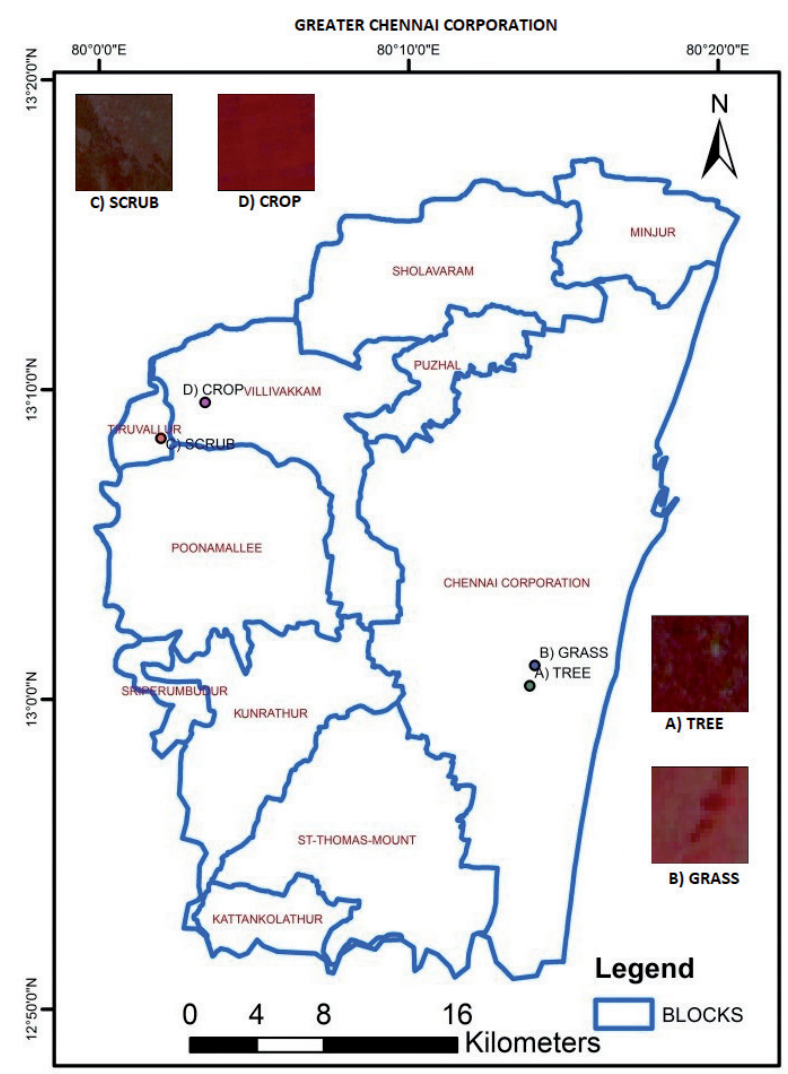

Fig. 1. Study area. 


\section{Data Set}

Indian Remote Sensing Satellite Sensor data products, Multispectral sensor (MSS) data of Linear Imaging Self Scanner IV (LISS IV) from Resourcesat-1 and Resourcesat-2 and Panchromatic (PAN) data of Cartosat-1 have been used for the green cover mapping of the study area. LISS IV (Resourcesat-1), LISS IV (Resourcesat-2) and PAN (Cartosat -1) have been taken with a spatial resolution of 5.8 and $2.5 \mathrm{~m}$ for 2005 and 2012, respectively. LISS IV consists of three spectral bands (Green, Red, NIR) whereas the PAN has a single band (visible range). QuickBird and Google Earth imagery have also been used for the accuracy assessment of the analysis.

\section{Methodology}

Fig. 2 details the process of green cover extraction using image processing and digitization. The methodology consists of three major steps: image preprocessing (error corrections and image fusion), mapping, and change detection.

\section{Radiometric and Geometric Error Corrections}

While capturing satellite images, radiometric and geometric errors are possible in nature due to the atmospheric and sensor system structure. Hence, corrections are applied to the errors to obtain the standard data products for the analysis. Moreover, radiometric deviation can be avoided by the corrections made in the images. In addition, the quantitative change detection analysis requires radiometric correction, as false changes occur in the classified maps if the radiometric calibration of multi-temporal dataset is not applied. Histogram stretching is employed to perform the corrections using a dark and bright pixel control set. In the present study, geometric correction of LISS IV imagery was carried out using orthorectified PAN which was generated from Cartosat-1 stereo pair and digital elevation model (DEM). Reprojection of radiometrically corrected LISS IV for 2005 was co-registered with LISS IV for 2012, using nearest neighborhood resampling method to retain the original radiometry of the datasets, whereas the UTM Zone 44 North coordinate system with WGS

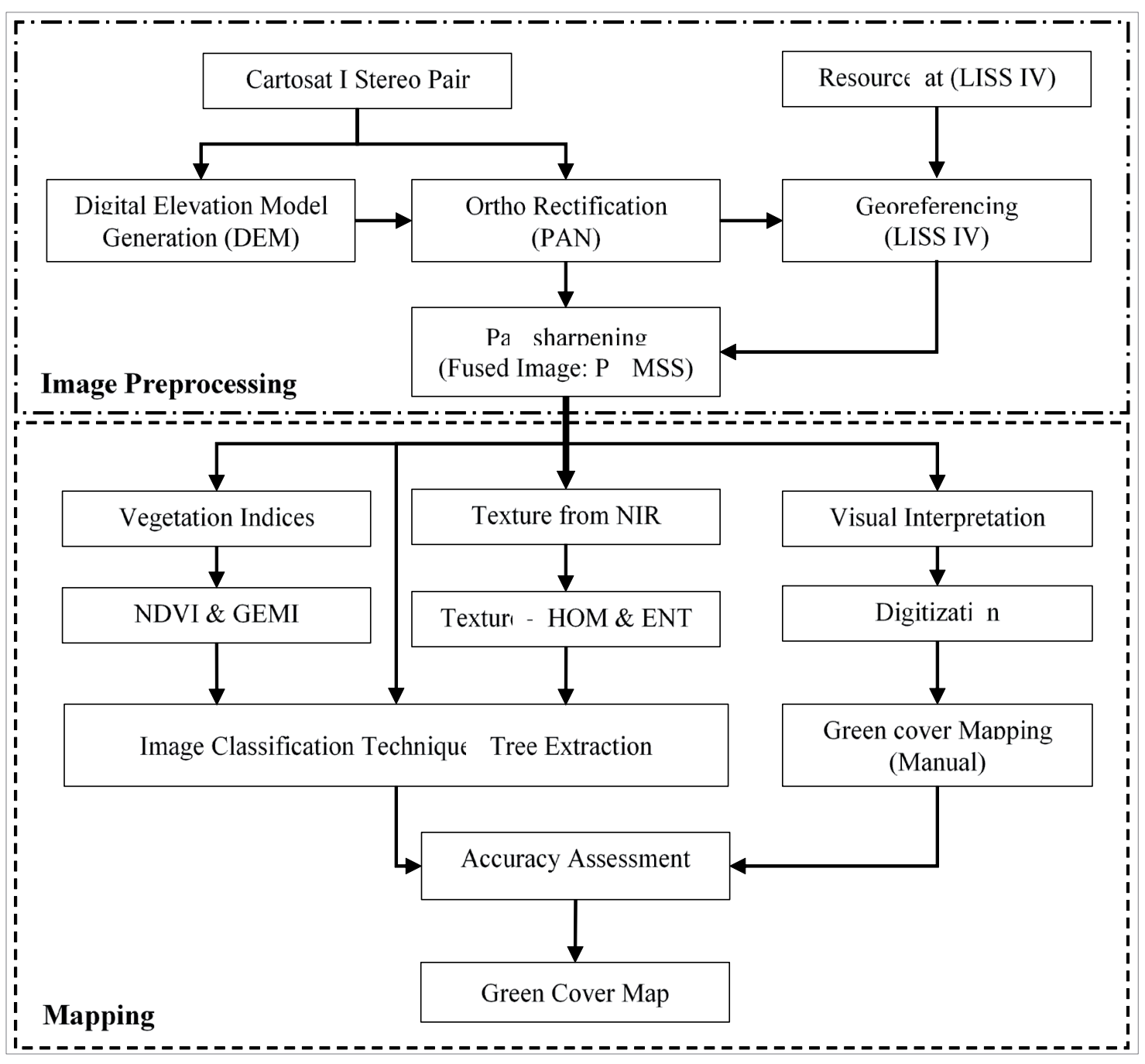

Fig. 2. Process of green cover extraction. 
84 was used for the datum projection. Root mean square error of less than a pixel was considered for the analysis.

\section{Pan-Sharpening or Image Fusion}

Color normalization and enhanced spatial resolution with relatively less spectral change for multi temporal panchromatic and multispectral data were performed using Brovey transform for pan-sharpening or resolution merging of LISS IV MSS and PAN [46-47]. An improved spatial resolution imagery was obtained from the pan-sharpened MSS of LISS IV for 2005 and 2012 after fusion.

\section{Mapping}

The mapping of green cover consists of two processes: image classification and visual interpretation. After visual inspection is carried out for training sites selection, image classification is applied to the entire dataset. Accuracy assessment is performed after green cover mapping. Vegetation texture is random in nature and is extracted from the raw images using Gray Level Cooccurrence Matrix (GLCM). Vegetation indices are classified based on vegetation categories, such as trees, grass and scrub.
Table 1 provides all possible vegetation indices (from LISS IV) of particular species with different canopy architectures and leaf structures available in the literature [19, 48]. An interactive data language (IDL) programming tool [49] is employed to evaluate the vegetation indices.

With the optimal vegetation indices and texture features from Near Infra Red (NIR) band, the pansharpened MSS data were stacked using conventional layer stacking techniques. Conventional pixel-based classification was applied to combined or stacked data with selected training samples. At the end of this classification process, the extracted tree covers of 2005 and 2012 were compared for the change detection.

\section{Change Detection}

The extracted tree covers from LISS IV of 2005 and 2012 images were converted into vector layer files for change detection and spatial analysis in which Boolean numbers were defined as an additional attribute. The Boolean value of 1 was applied for tree cover areas, while the Boolean value of 0 was applied to remaining attributes in 2005 and 2012. Unchanged (11), increased (01) and decreased areas (10) were identified with the defined Boolean numbers using union analysis and AND operation in the resultant change detection layer.

Table 1. Various Vegetation Indices.

\begin{tabular}{|c|c|}
\hline Indices & Formula \\
\hline DVI, Difference Vegetation Index & NIR - Red \\
\hline GDVI, Green Difference Vegetation Index & NIR - Green \\
\hline GEMI, Global Environmental Monitoring Index & $\begin{array}{c}\eta^{*}(1-0.25 * \dot{\eta})-[(\operatorname{Red}-0.125) /(1-\operatorname{Red})] \\
\text { where } \eta \dot{\eta}=\left[2 *\left(\mathrm{NIR}^{2} \operatorname{Red}^{2}\right)+1.5 * \mathrm{NIR}+0.5 * \operatorname{Red}\right] /(\mathrm{NIR}+\operatorname{Red}+0.5)\end{array}$ \\
\hline GNDVI, Green Normalized Difference Vegetation Index & (NIR - Green) / (NIR + Green) \\
\hline GRVI, Green Ratio Vegetation Index & NIR / Green \\
\hline GSAVI, Green Soil Adjusted Vegetation Index & {$[(\mathrm{NIR}-$ Green $) /(\mathrm{NIR}+$ Green $+\mathrm{L})] *(1+\mathrm{L})$, where $\mathrm{L}=0.5$} \\
\hline MSAVI, Modified Soil Adjusted Vegetation Spectral Index & {$\left[2 * \mathrm{NIR}+1-\sqrt{ }\left\{(2 * \mathrm{NIR}+1)^{2}-8 *(\mathrm{NIR}-\mathrm{Red})\right\}\right] / 2$} \\
\hline MSR, Modified Simple Ratio & $\operatorname{Red} /(\mathrm{NIR} / \operatorname{Red}+1)^{\wedge} 0.5$ \\
\hline MTVI, Modified Triangular Vegetation Index & $\begin{array}{l}{\left[1.5\left(1.2^{*}(\mathrm{NIR}-\text { Green })-2.5(\text { Red }- \text { Green })\right] /[(2\right.} \\
\left.\quad \mathrm{NIR}+1) 2-\left(6 \mathrm{NIR}-5 \mathrm{Red}^{\wedge} 0.5\right)-0.5\right]^{\wedge} 0.5\end{array}$ \\
\hline NDVI, Normalized Difference Vegetation Index & (NIR - Red) / (NIR + Red) \\
\hline NG, Normalized Green & Green / (NIR + Red + Green) \\
\hline NNIR, Normalized Near Infrared & NIR / (NIR + Red + Green) \\
\hline NR, Normalized Red & Red / (NIR + Red + Green) \\
\hline OSAVI, Optimized Soil Adjusted Vegetation Index & $(\mathrm{NIR}-\mathrm{Red}) /(\mathrm{NIR}+\mathrm{Red}+0.16)$ \\
\hline RDVI, Renormalized Difference Vegetation Index & $(\mathrm{NIR}-\mathrm{Red}) /(\mathrm{NIR}+\mathrm{Red})^{\wedge} 0.5$ \\
\hline RVI, Ratio Vegetation Index or Simple Ratio & NIR / Red \\
\hline SAVI, Soil Adjusted Vegetation Index & {$[(\mathrm{NIR}-\mathrm{Red}) /(\mathrm{NIR}+\mathrm{Red}+\mathrm{L})] *(1+\mathrm{L})$, where $\mathrm{L}=0.5$} \\
\hline
\end{tabular}




\section{Constraints in Mapping of Green Cover in the Study}

In this study, Machine Learning (ML) based Decision Tree Classifier (DTC) was used for the extraction of trees, and accuracy assessment was carried out using known training sites. The remaining LU/LC categories were not considered for the analysis, as the study focused on delineation of green covers. Also, the water bodies and restricted areas were masked and so were not considered for the analysis. Further, the tree covers in the reserved forest areas were considered as unchanged area. More than two-pixel size areas of LISS IV were taken as the threshold limit and were considered for the detection analysis. The masked areas of water body and reserved forest boundary were prepared by using the Survey of India Toposheets and thematic layers of Space based Information Support for Decentralized Planning (SISDP), prepared by the National Remote Sensing Agency of India [50]. In addition, the imagery clipping tool was used for the omission of the restricted area.

\section{Results and Discussion}

\section{Training Sites and Optimization of Indices}

Equal sample sizes $(25 \times 25$ pixels $)$ of tree, grass, scrub and crop categories were taken as sample or training subsets for both PS-MSS LISS IV of 2005 and 2012, as given in Fig. 1. The high-resolution remote sensing data LISS IV produced better textures for window sizes $11 \times 11$ and $13 \times 13$ and were adopted for the extraction of random texture pattern. Principal component analysis was carried out for optimal derived textures. For the vegetation categories, homogeneity (HOM) and entropy (ENT) derived from GLCM were used for better accuracies [33]. The developed IDL script was applied to the training subsets and mean statistics was derived for the vegetation indices. Table 2 gives the averaged vegetation indices for the subsets of pan-sharpened LISS IV for 2005 and 2012. NDVI and GEMI are chosen as optimal vegetation indices from Table 2, while other vegetation indices overlap between categories.

\section{Image Classification}

Combined spectral and derived parameters of texture and vegetation indices produced better accuracy than individual per pixel classification [33]. Hence, the band or imagery of NDVI and GEMI of vegetation indices and HOM and ENT of spatial texture categories were generated from NIR. In addition, spectral bands of PS-MSS of LISS IV for 2005 were stacked and the procedure was repeated for PS-MSS LISS IV for 2012. Then, DTC was applied to the stacked dataset to minimize time consumption of digitization process. Since DTC is a consecutive IF ELSE function,

Table 2. Vegetation Indices from LISS IV.

\begin{tabular}{|c|c|c|c|c|}
\hline Indices & Tree & Crop & Scrub & Grass \\
\hline DVI & 85.7951 & 154.9220 & 88.0660 & 64.0430 \\
\hline GDVI & 63.5532 & 128.1237 & 67.6878 & 53.3752 \\
\hline GEMI & -7372.4552 & -24003.5621 & -7900.6664 & -4055.0388 \\
\hline GNDVI & 0.2383 & 0.3870 & 0.2429 & 0.1912 \\
\hline GRVI & 1.6294 & 2.2688 & 1.6480 & 1.4734 \\
\hline GSAVI & 0.3568 & 0.5796 & 0.3637 & 0.2863 \\
\hline MSAVI & 0.5188 & 0.6742 & 0.5067 & 0.3845 \\
\hline MSR & 44.8782 & 36.8122 & 48.3185 & 63.0002 \\
\hline MTVI & 0.6003 & 0.7222 & 0.5725 & 0.4100 \\
\hline NDVI & 0.3517 & 0.5097 & 0.3418 & 0.2388 \\
\hline NG & 0.2935 & 0.2501 & 0.2899 & 0.2960 \\
\hline NNIR & 0.4775 & 0.5662 & 0.4766 & 0.4360 \\
\hline NR & 0.2289 & 0.1837 & 0.2335 & 0.2679 \\
\hline OSAVI & 0.3515 & 0.5094 & 0.3416 & 0.2386 \\
\hline RDVI & 5.4918 & 8.8838 & 5.4854 & 3.9101 \\
\hline RVI & 2.0931 & 3.0939 & 2.0556 & 1.6288 \\
\hline SAVI & 0.5265 & 0.7633 & 0.5118 & 0.3575 \\
\hline
\end{tabular}


the consecutive IF conditions of NDVI, GEMI, HOM, ENT and spectral bands of green, red, and NIR were used to train and extract the tree cover in LISS IV images.

From Table 2, the initial IF condition with NDVI values of 0.22 to 0.52 were used for extracting the vegetation cover, while masking other LU/LC categories. Further, tree and scrub categories were delineated using the IF condition with GEMI values of -25000 to -23000 for crop, -5000 to -3000 for grass and -9000 to -6000 for tree and scrub categories. Then, the HOM values of 0.15 to 0.25 for tree and the ENT values of 4.4 to 4.6 for tree were used to extract tree, while masking other vegetation categories, especially the scrub. The reason is that in nature crop and grass have a fine texture while tree has a coarser texture than scrub. In addition, the band values of red from 77 to 80 , green from 99 to 102 and NIR from 163 to 166 were used in DTC to extract tree cover from the data sets of 2005 and 2012.

\section{Accuracy Evaluation}

An accuracy assessment was performed using stratified random samples of tree cover from the training class. This produced $88.4 \%$ and $89.6 \%$ classification accuracies for 2005 and 2012 data sets, respectively.
Since this is a quantitative study, the extracted tree cover and Google imageries were layered on each other to identify the discrepancies in the extracted tree covers and to ensure the improvement in accuracy using digitization with the visual interpretation, based on user knowledge. Figs 3 and 4 present the images of LISS IV of 2005 and 2012 and the corresponding extracted tree covers of 2005 and 2012, respectively.

\section{Green Cover Change Analysis}

A visual interpretation is possible for LISS IV and the extracted green covers. Figs 3 and 4 show that the spatial distribution of the green covers for 2005 and 2012 clusters at the center of Chennai rather than other areas except reserved forest. Hence, the reserved forest areas are identified through the high density tree cover. Guindy, Vandalur, Nallur and Alamadi reserved forest areas are located in Chennai, Kanchipuram and Thiruvallur districts, respectively, and are identified using the visual interpretation. The tree cover maps of 2005 and 2012, generated from these high resolution images, were used for conventional change detection procedures.

If Fig. 5 reveals the change detection, Table 3 presents the corresponding statistics for tree cover. It is clear from Fig. 5 that the visual interpretation is possible

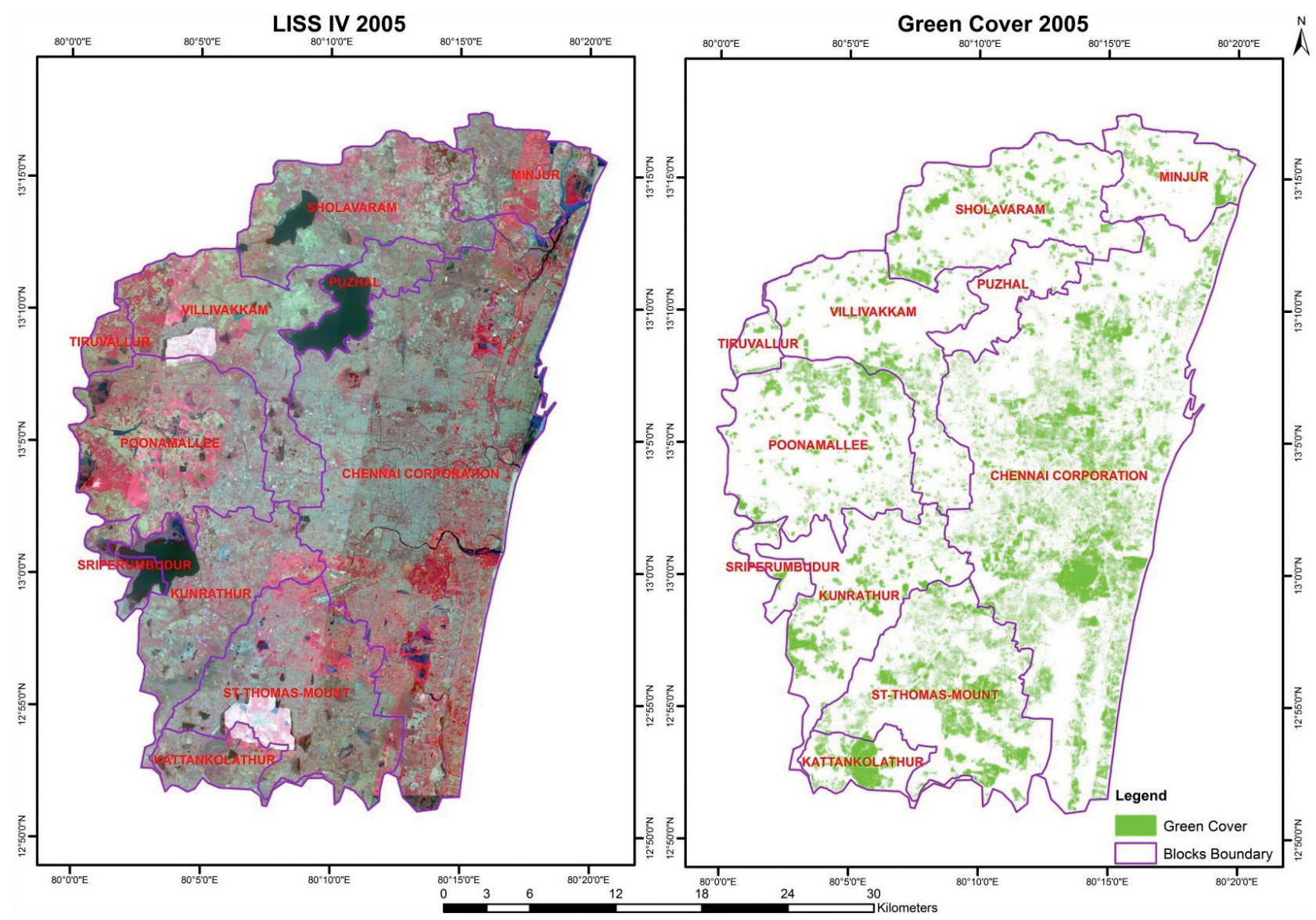

Fig. 3. LISS IV and extracted green cover (2005). 


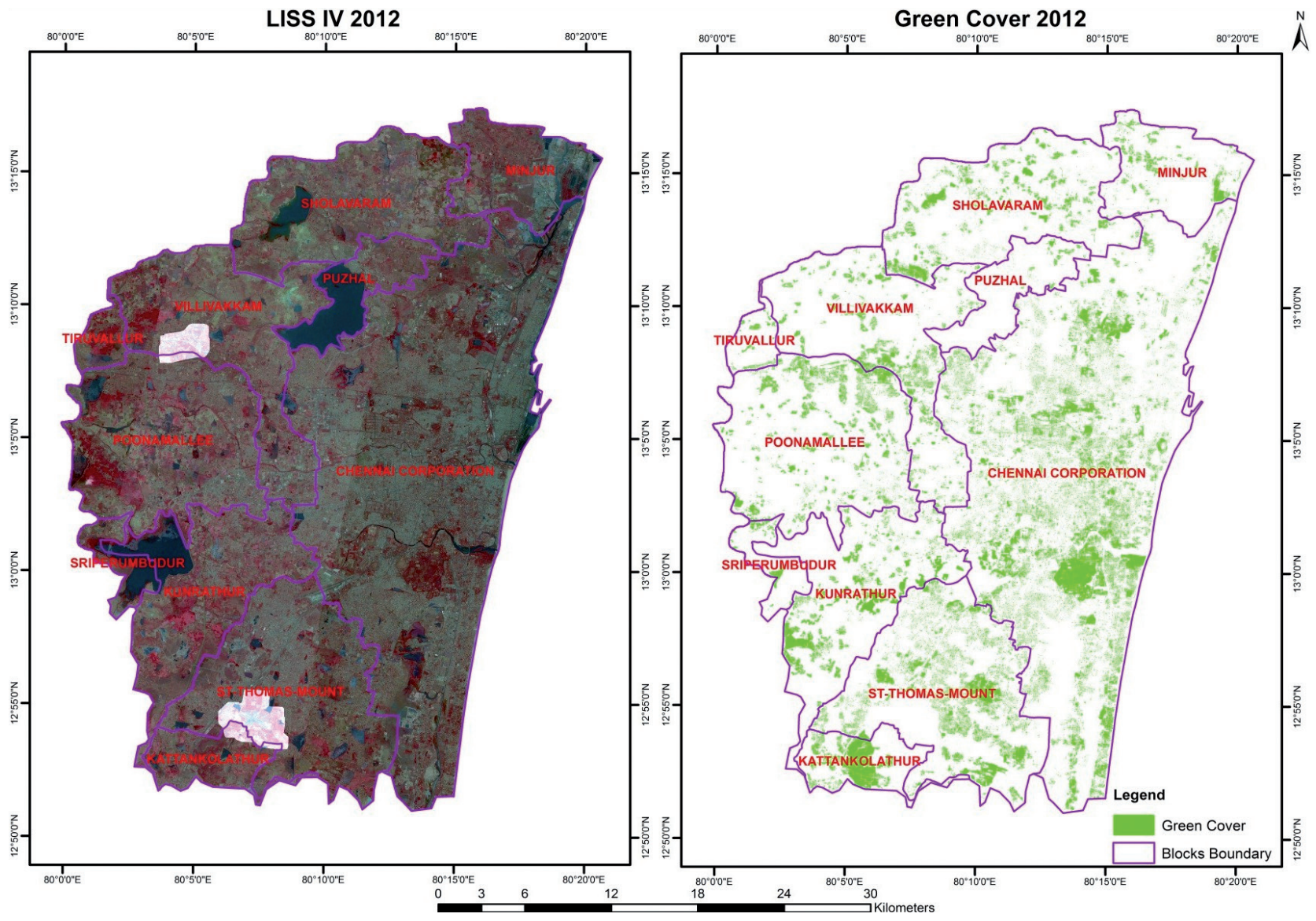

Fig. 4. LISS IV and extracted green cover (2012).

Table 3. Change detection Statistics - Block - wise analysis.

\begin{tabular}{|c|c|c|c|c|c|c|}
\hline \multirow{2}{*}{ Blocks } & \multirow{2}{*}{$\begin{array}{c}\text { Administrative area, } \\
\mathrm{km}^{2}\end{array}$} & \multicolumn{2}{|c|}{ Green cover (tree), $\mathrm{km}^{2}$} & \multicolumn{2}{c|}{ Green cover change w.r.t } \\
\cline { 3 - 7 } & 2005 & 2012 & Change & Administrative boundary, $\%$ & $2005, \%$ \\
\hline $\begin{array}{c}\text { Chennai } \\
\text { Corporation }\end{array}$ & 440.6181 & 79.7415 & 69.1005 & -10.6411 & -2.4150 & -13.3445 \\
\hline Kattankolathur & 31.4870 & 8.7344 & 8.7630 & 0.0286 & 0.0907 & 0.3274 \\
\hline Kunrathur & 105.5063 & 12.1344 & 13.0846 & 0.9502 & 0.9006 & 7.8306 \\
\hline Minjur & 56.4976 & 4.0961 & 3.8659 & -0.2302 & -0.4074 & -5.6200 \\
\hline Poonamallee & 138.0109 & 13.7578 & 12.7571 & -1.0007 & -0.7251 & -7.2737 \\
\hline Puzhal & 37.081 & 0.6482 & 0.7429 & 0.0947 & 0.2554 & 14.6097 \\
\hline Sholavaram & 116.3193 & 10.5458 & 10.7835 & 0.2378 & 0.2044 & 2.2549 \\
\hline Sriperumbudur & 16.4224 & 1.2516 & 1.2377 & -0.0139 & -0.0846 & -1.1106 \\
\hline St-Thomas Mount & 144.4444 & 25.8976 & 21.3360 & -4.5616 & -3.1580 & -17.6140 \\
\hline Thiruvallur & 12.9428 & 1.2176 & 1.1359 & -0.0818 & -0.6317 & -6.7181 \\
\hline Villivakkam & 119.0217 & 9.4326 & 10.2235 & 0.7909 & 0.6645 & 8.3848 \\
\hline Total & 1218.3515 & 167.4576 & 153.0306 & -14.4270 & -1.1841 & -8.6153 \\
\hline
\end{tabular}




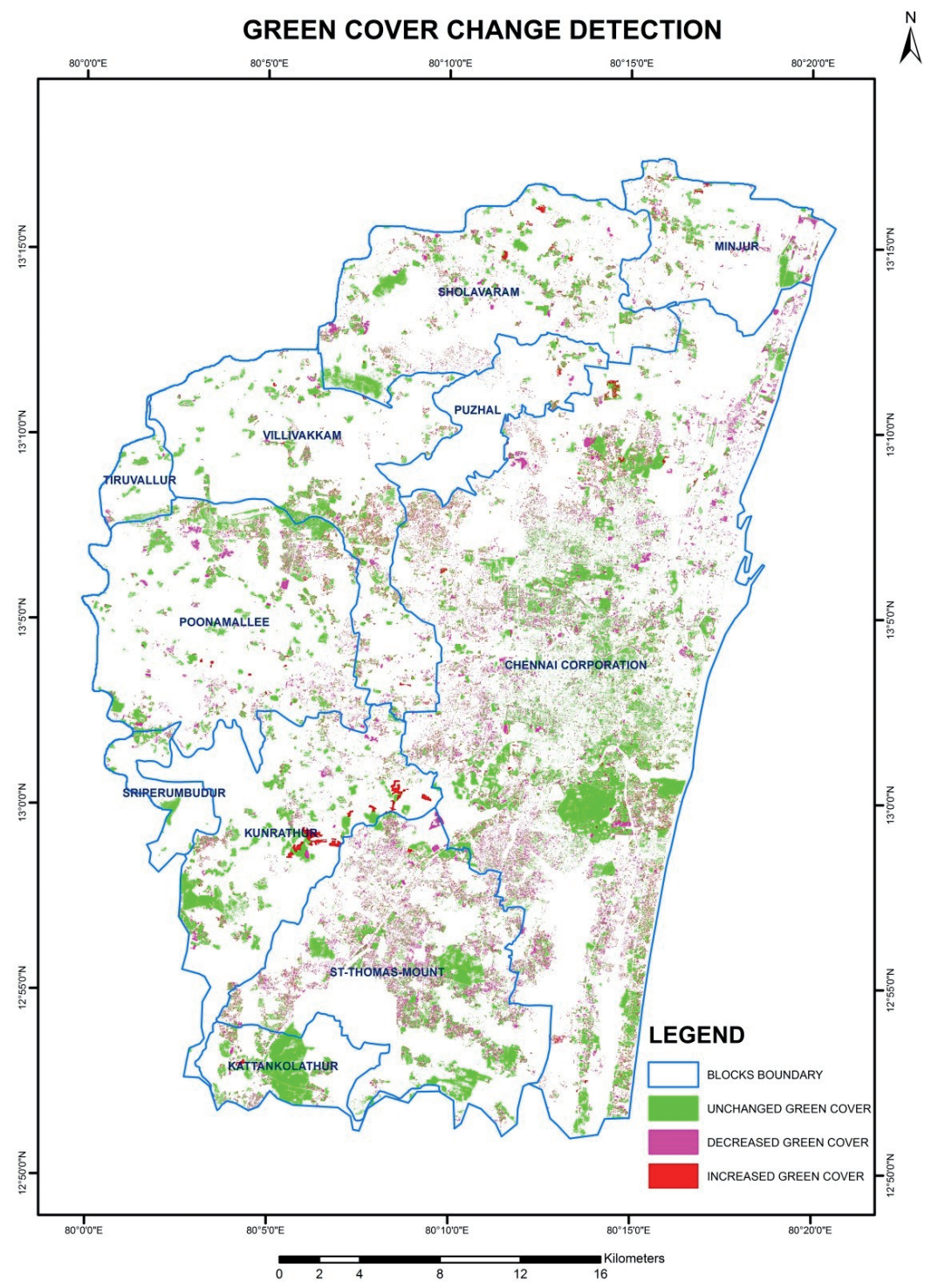

Fig. 5. Change detection after union overlay analysis.

in high degree to identify the tree cover changes using spatial distribution in terms of decreased (-ve) and increased $(+v e)$ categories. As Table 3 indicates, the tree cover in Chennai metropolis decreased abruptly, while the remaining blocks fall under moderate change in increase or decrease categories. It is evident from Fig. 5 that agricultural and plantation activities near refineries have increased in Kunrathur, Sholavaram, Chennai metropolis and some areas of Minjur. Further, Fig. 6 displays the decrease and increase in tree cover at selected sample locations.

\section{Reasons for the Reduction of Tree Cover}

Figs. 3, 4 and 5 clearly show a decrease in tree cover in Chennai metropolis, mainly due to urbanization and development activities. Frequent cyclones have also contributed to the decreased tree cover in Chennai metropolis [51]. Decrease in tree cover is observed near and the buffer zones of outer ring road (ORR) in sub- urban areas due to its development from 2010 onwards [52]. A drastic decrease in tree cover is observed in the commercial built-up areas, largely due to urbanization and industrial development in sub-urban areas.

\section{Usefulness of this Analysis}

As per the guidelines for the conservation, development and management of Urban Greens from Forest Policy Division, Ministry of Environment, Forests \& Climate Change, India, $33 \%$ of the geographical areas of the country should be under forest and tree cover to maintain the environmental balance. As this analysis shows a drastic reduction in forest and tree cover, it will be useful to policy makers and administrators for the development of master plans for metropolitan cities to ensure green cover through a proper preparation of guidelines for maintaining, enhancing, pruning, and lopping of tree cover, resource assessment, and financial support to tree cover [53]. 


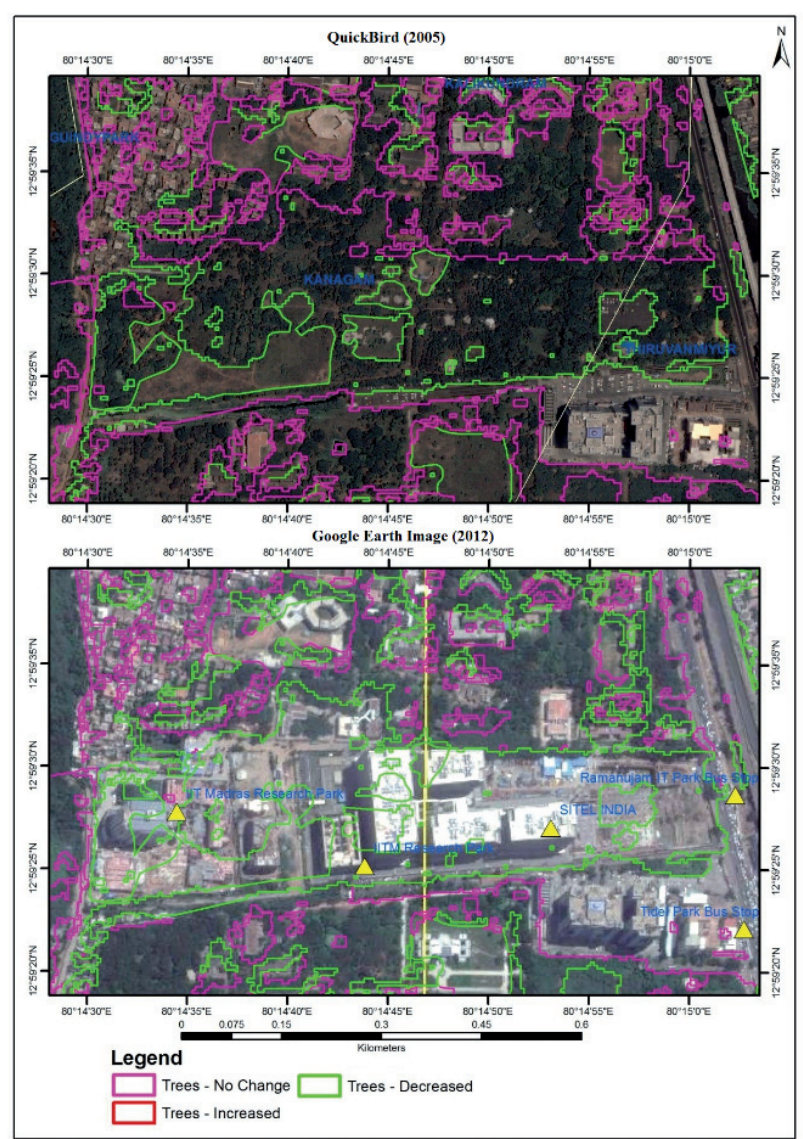

Fig. 6. Decrease and increase in tree cover at selected locations.

\section{Conclusions}

The literature review reveals that urban green cover mapping measures the biodiversity of the system using LU/LC indirectly with the help of remote sensing techniques. In this study, LISS IV for 2005 and 2012 and Cartosat I PAN images of CMA were fused in the analysis for the better spatial resolution. Vegetation indices and texture analysis were performed to extract the green cover applying the decision tree classifier. The change detection results reveal that the green cover of CMA is reduced from $167.46 \mathrm{~km}^{2}$ in 2005 to $153.03 \mathrm{~km}^{2}$ in 2012 . The overall green cover area for 2012 decreased by $1.18 \%$ with respect to CMA administrative boundary. The actual green cover decreased by $8.62 \%$ for 2012 due to the increase in population density, urbanization, industrial development, frequent cyclones and development of ORR. It is observed that the green cover (tree) decreased drastically in Chennai Corporation and its sub-urban blocks. Hence, this study recommends planting activities on a large scale to regain and maintain the balanced ecosystem. This analysis will be useful to policy makers and administrators for preserving the green cover of Chennai Metropolitan Area.

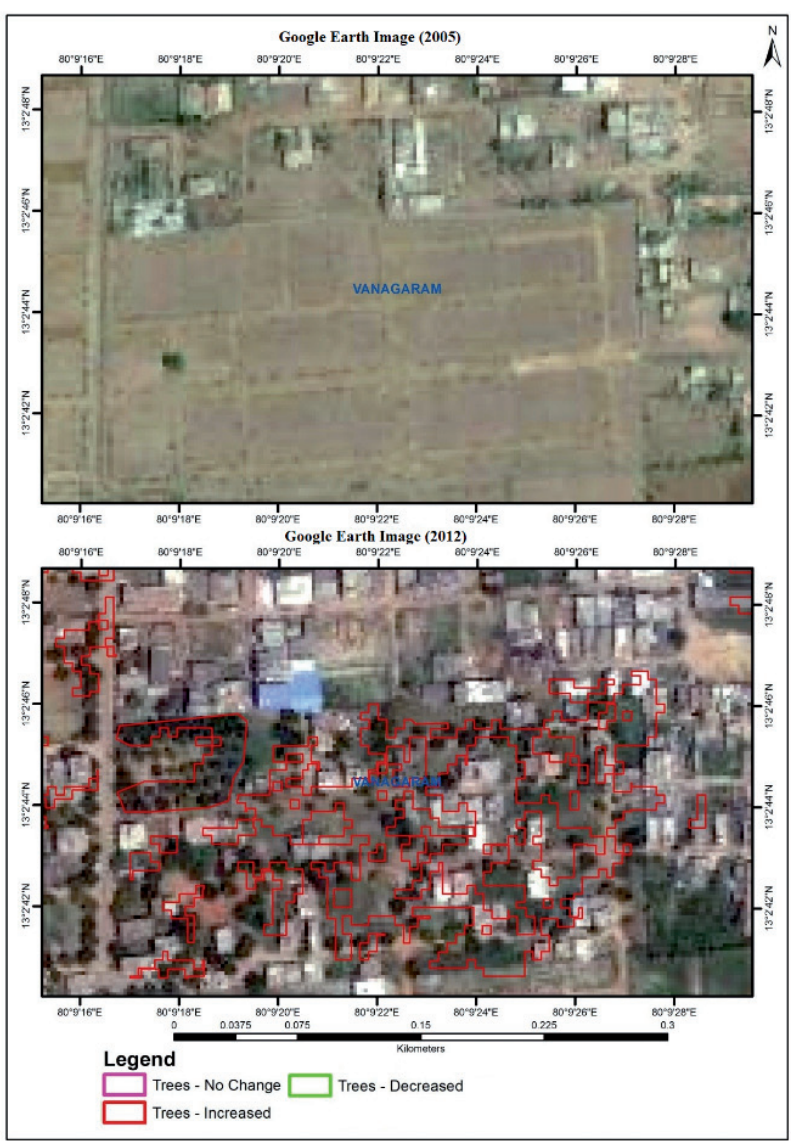

\section{Acknowledgement}

The authors would like to thank the Institute of Remote Sensing, Anna University, India, for the satellite data and technical support.

\section{Conflict of Interest}

The authors declare no conflict of interest.

\section{References}

1. JANA C., MANDAL D., SHRIMALI S.S., ALAM N.M., KUMAR R., SENA D.R., KAUSHAL R. Assessment of urban growth effects on green space and surface temperature in Doon Valley, Uttarakhand, India. Environmental Monitoring and Assessment, 192 (4), 1, 2020.

2. TURAGA R.M.R., JHA-THAKUR U., CHAKRABARTI S., HOSSAIN D. Exploring the role of Urban Green Spaces in "smartening" cities in India. Impact Assessment and Project Appraisal, 1, 2019.

3. HUA L., ZHANG X., NIE Q., SUN F., TANG L. The impacts of the expansion of urban impervious surfaces on urban heat islands in a coastal city in China. Sustainability (Switzerland), 12 (2), 1, 2020. 
4. SHARMA K., JALAN S. Change assessment of urban green spaces of Dehradun city using image derived parameters. Transactions of the Institute of Indian Geographers, 35 (1), 63, 2013.

5. RAMAIAH M., AVTAR R. Urban green spaces and their need in cities of rapidly urbanizing India: A Review. Urban Science, 3 (3), 94, 2019.

6. CETIN M. Using GIS analysis to assess urban green space in terms of accessibility: Case study in Kutahya. International Journal of Sustainable Development and World Ecology, 22 (5), 420, 2015.

7. MIETTINEN J., GAVEAU D.L.A., LIEW S.C. Comparison of visual and automated oil palm mapping in Borneo. International Journal of Remote Sensing, 40 (21), 8174, 2019.

8. FENG Q., LIU J., GONG J. UAV Remote sensing for urban vegetation mapping using random forest and texture analysis. Remote Sensing, 7 (1), 1074, 2015.

9. ZHANG K., HU B. Individual urban tree species classification using very high spatial resolution airborne multi-spectral imagery using longitudinal profiles. Remote Sensing, 4 (6), 1741, 2012.

10. SHISHIR S., TSUYUZAKI S. Hierarchical classification of land use types using multiple vegetation indices to measure the effects of urbanization. Environmental Monitoring and Assessment, 190 (6), 1, 2018.

11. SCHOLZ M., UZOMAH V.C., AL-FARAJ F.A.M. Potential tree species for use in urban areas in temperate and oceanic climates. Heliyon, 2 (9), 1, 2016.

12. ASOKAN A., ANITHA J. Change detection techniques for remote sensing applications: a survey. Earth Science Informatics. 12 (2), 143, 2019.

13. FONJI S.F., TAFF G.N. Using satellite data to monitor land-use land-cover change in North-eastern Latvia. SpringerPlus, 3 (61), 1, 2014.

14. SINGH R.P., SINGH N., SINGH S., MUKHERJEE S. Normalized Difference Vegetation Index (NDVI) based classification to assess the change in Land Use/Land Cover (LULC) in Lower Assam, India. International Journal of Advanced Remote Sensing and GIS, 5 (1), 1963, 2016.

15. KHAN S., QASIM S., AMBREEN R., SYED Z.U.H. Spatio-Temporal analysis of Landuse/Landcover change of district Pishin using satellite imagery and GIS. Journal of Geographic Information System, 8 (3), 361, 2016.

16. KAMALI M.E., HASHEMI H., BERNDTSSON R., DANESHKAR A.P., KAZEMI M. Impact of spatiotemporal land-use and land-cover changes on surface urban heat islands in a semiarid region using Landsat data. International Journal of Digital Earth, 2020.

17. HATFIELD J.L., PRUEGER J.H., SAUER T.J., DOLD C., O'BRIEN P., WACHA K. Applications of vegetative indices from remote sensing to agriculture: Past and future. Inventions, 4, 71, 2019.

18. LAWLEY V., LEWIS M., CLARKE K., OSTENDORF B. Site-based and remote sensing methods for monitoring indicators of vegetation condition: An Australian review. Ecological Indicators, 60, 1273, 2016.

19. XUE J., SU B. Significant remote sensing vegetation indices: A review of developments and applications. Journal of Sensors, 2017.

20. WASER L.T., GINZLER C., KUECHLER M., BALTSAVIAS E., HURNI L. Semi-automatic classification of tree species in different forest ecosystems by spectral and geometric variables derived from Airborne Digital Sensor (ADS40) and RC30 data. Remote Sensing of Environment, 115 (1), 76, 2011.
21. WANG Y., ZHU X., WU B. Automatic detection of individual oil palm trees from UAV images using HOG features and an SVM classifier. International Journal of Remote Sensing, 40 (19), 7356, 2019.

22. WANG X., SU C., FENG C., ZHANG X. Land use mapping based on composite regions in aerial images. International Journal of Remote Sensing, 39 (23), 8885, 2018.

23. WOOD E.M., PIDGEON A.M., RADELOFF V.C., KEULER N.S. Image texture as a remotely sensed measure of vegetation structure. Remote Sensing of Environment, 121, 516, 2012.

24. VIÑA A., VIÑA V., LIU W., ZHOU S., HUANG J., LIU J. Land surface phenology as an indicator of biodiversity patterns. Ecological Indicators, 64, 281, 2016.

25. AVOLA G., DI GENNARO S.F., CANTINI C., RIGGI E., MURATORE F., TORNAMBÈ C., MATESE A. Remotely sensed vegetation indices to discriminate field-grown olive cultivars. Remote Sensing, 11 (10), 1242, 2019.

26. GITELSON A.A. Remote estimation of crop fractional vegetation cover: the use of noise equivalent as an indicator of performance of vegetation indices. International Journal of Remote Sensing, 34 (17), 6054, 2013.

27. KROSS A., MCNAIRN H., LAPEN D., SUNOHARA M., CHAMPAGNE C. Assessment of RapidEye vegetation indices for estimation of leaf area index and biomass in corn and soybean crops. International Journal of Applied Earth Observation and Geoinformation, 34 (1), 235, 2015.

28. REGNIERS O., BOMBRUN L., LAFON V., GERMAIN C. Supervised classification of very high resolution optical images using Wavelet-based textural features. IEEE Transactions on Geoscience and Remote Sensing, 54 (6), 3722, 2016.

29. BURNETT M.W., WHITE T.D., MCCAULEY D.J., DE LEO G.A., MICHELI F. Quantifying coconut palm extent on Pacific islands using spectral and textural analysis of very high resolution imagery. International Journal of Remote Sensing, 40 (19), 7329, 2019.

30. WANG L., SHI C., DIAO C., JI W., YIN D. A survey of methods incorporating spatial information in image classification and spectral unmixing. International Journal of Remote Sensing, 37 (16), 3870, 2016.

31. FERREIRA M.P., WAGNER F.H., ARAGÃO L.E.O.C., SHIMABUKURO Y.E., DE SOUZA F.C.R. Tree species classification in tropical forests using visible to shortwave infrared WorldView-3 images and texture analysis. ISPRS Journal of Photogrammetry and Remote Sensing, 149, 119, 2019.

32. ZHANG X., CUI J., WANG W., LIN C. A study for texture feature extraction of high-resolution satellite images based on a direction measure and gray level co-occurrence matrix fusion algorithm. Sensors, 17 (7), 1474. 2017.

33. VENKATESAN C., MURUGASAN R. Optimization of feature extraction from high resolution satellite imagery for urban environment. Ecology, Environment and Conservation, 24 (1), 355, 2018.

34. FENG S., ZHAO J., LIU T., ZHANG H., ZHANG Z., GUO $X$. Crop type identification and mapping using machine learning algorithms and Sentinel-2 time series data. IEEE Journal of Selected Topics in Applied Earth Observations and Remote Sensing, 12 (9), 3295, 2019.

35. MENG J., LI S., WANG W., LIU Q., XIE S., MA W. Mapping forest health using spectral and textural information extracted from SPOT-5 satellite images. Remote Sensing, 8 (9), 179, 2016. 
36. HARALICK R.M. Statistical and structural approaches to texture. Proceedings of the IEEE, 67 (5), 786, 1979.

37. HUMEAU-HEURTIER A. Texture feature extraction methods: A survey. IEEE Access, 7, 8975, 2019.

38. WAN S., CHANG S.H. Crop classification with WorldView-2 imagery using Support Vector Machine comparing texture analysis approaches and grey relational analysis in Jianan Plain, Taiwan. International Journal of Remote Sensing, 40 (21), 8076, 2019.

39. GOSPODAREK J., KLIMEK-KOPYRA A., RUSIN M. Suitability of NDVI index to pea condition evaluation at diverse phosphorus fertilization. Italian Journal of Agronomy, 15 (1), 2020.

40. ZAIDI S.M., AKBARI A., ABU SAMAH A., KONG N., GISEN J. Landsat-5 Time Series Analysis for Land Use/ Land Cover Change Detection Using NDVI and SemiSupervised Classification Techniques. Polish Journal of Environmental Studies, 26 (6), 2833, 2017.

41. SHAHEEN H., BATOOL A., GILLANI S.F., UL ISLAM DAR M.E., HABIB T., AZIZ S. Diversity and distribution of invasive plant species in suburban vegetation of Kashmir Himalayas. Polish Journal of Environmental Studies, 28 (4), 2823, 2019.

42. TOKATLI C. Drinking water quality of a rice land in Turkey by statistical and GIS perspectives. Polish Journal of Environmental Studies, 23 (6), 2247, 2014.

43. CMDA. Chennai Metropolitan Area - Profile. Ministry of Housing and Urban Development Department, Government of Tamilnadu. Available online: http://www. cmdachennai.gov.in/ (accessed on 05 September 2020).

44. CENSUS. Census-2011. Office of the Registrar General \& Census Commissioner, India. https://censusindia.gov. in/2011-common/censusdata2011.html (accessed on 05 September 2020).

45. TNSLURB. Green Chennai City. Tamil Nadu State Land Use Research Board, State Planning Commission, Government of Tamil Nadu. Available online: http://www. spc.tn.gov.in/spc_reports/Green_chennai.pdf (accessed on 05 September 2020)
46. ESRI. Fundamentals of panchromatic sharpening Available online: https://desktop.arcgis.com/en/arcmap/ latest/manage-data/raster-and-mages/fundamentals-ofpanchromatic-sharpening.htm (accessed on 05 September 2020).

47. CANTY M.J. Panchromatic Sharpening. In Book of Image analysis, classification and change detection in remote sensing: with algorithms for ENVI/IDL and Python (pp. 176-183). CRC Press/Taylor \& Francis Group, $3^{\text {rd }}$ Edition, 2014.

48. AGAPIOU A., HADJIMITSIS D., ALEXAKIS D. Evaluation of Broadband and Narrowband Vegetation Indices for the Identification of Archaeological Crop Marks. Remote Sensing, 4 (12), 3892, 2012.

49. ENVI. IDL - Interactive Data Language. Harris Geospatial Solutions, Inc. Available online: https://www. harrisgeospatial.com/docs/using_idl_home.html (accessed on 05 September 2020).

50. NRSC. Space based Information Support for Decentralised Planning (SISDP). National Remote Sensing Centre (NRSC), Indian Space Research Organisation (ISRO). Available online: https://www.nrsc.gov.in/readmore ruraldevop_sisdp?language_content_entity $=$ en (accessed on 05 September 2020).

51. IMD, Cyclone eAtlas. India Meteorological Department. Available online: http://14.139.191.203/login.aspx?ReturnU $\mathrm{rl}=\% 2 \mathrm{fViewByIdentifiers.aspx}$ (accessed on 23 December 2020).

52. ORR. Outer Ring Road. Chennai. Metropolitan Development Authority, Government of Tamilnadu. Available online: http://www.cmdachennai.gov.in/ outerringroad.html \& http://www.cmdachennai.gov.in/ pdfs/go/go10.pdf (accessed on 23 December 2020).

53. MOEF. Guidelines for conservation, development and management of Urban Greens. Forest Policy Division, Ministry of Environment. Forests \& Climate Change, India. Available online: http://moef.gov.in/wp-content/ uploads/2017/07/draft-fp-24714.pdf (assessed on 23 December 2020). 